\title{
Retraction Note: River wetland landscape planning and design from low-carbon perspective
}

\author{
Qin $\mathrm{Li}^{1} \cdot$ Peng Wang ${ }^{2}$ \\ Published online: 6 December 2021 \\ C) Saudi Society for Geosciences 2021
}

Retraction Note: Arabian Journal of Geosciences (2021) 14: 863 https://doi.org/10.1007/s12517-021-07262-5

The Editor-in-Chief and the Publisher have retracted this article because the content of this article is nonsensical. The peer review process was not carried out in accordance with the Publisher's peer review policy. The authors have not responded to correspondence regarding this retraction.

The original article can be found online at https://doi.org/10.1007/ s12517-021-07262-5.

Qin $\mathrm{Li}$

liq20150525@163.com

Peng Wang

wpeng.up@foxmail.com

1 School of Design, East China Normal University, Shanghai 200062, China

2 Research Institute of Forestry Policy and Information, Chinese Academy of Forestry, Beijing 100091, China 